\title{
Noncardiogenic Pulmonary Edema
}

National Cancer Institute

\section{Source}

National Cancer Institute. Noncardiogenic Pulmonary Edema. NCI Thesaurus. Code C124947.

Pulmonary edema that is not a result of cardiac dysfunction. 